\title{
Molecular mechanisms of hyperglycemia and cardiovascular-related events in critically ill patients: rationale for the clinical benefits of insulin therapy
}

\author{
This article was published in the following Dove Press journal: \\ Clinical Epidemiology \\ 10 December 2010 \\ Number of times this article has been viewed
}

\author{
Samer Ellahham \\ Paragon Cardiovascular Foundation, \\ Falls Church, VA, USA
}

Correspondence: Samer Ellahham Paragon Cardiovascular Foundation, 370 I S George Mason Drive,

Falls Church,VA, USA

Tel + I (703) 379-9202

Email samerI@ix.netcom.com

\begin{abstract}
Newly recognized hyperglycemia frequently occurs with acute medical illness, especially among patients with cardiovascular disease (CVD). Hyperglycemia has been linked to increased morbidity and mortality in critically ill patients, especially when it is newly recognized. Increased rates of reinfarction, rehospitalization, major cardiovascular events, and death in CVD patients have also been found. An expanding body of literature describes the benefits of normalizing hyperglycemia with insulin therapy in hospitalized patients. This article reviews several underlying mechanisms thought to be responsible for the association between hyperglycemia and poor outcomes in critically ill patients and those with cardiovascular events, as well as the biologic rationale for the benefits of insulin therapy in these patients.
\end{abstract}

Keywords: hyperglycemia, diabetes, cardiovascular disease, critical illness, insulin

\section{Introduction}

Estimates from 2007 indicate that 23.6 million people in the United States (7.8\%) have diabetes, among whom 5.7 million are undiagnosed. ${ }^{1}$ An additional 57 million American adults may have prediabetes (based on the prevalence of impaired fasting glucose). ${ }^{1}$ Hyperglycemia also frequently occurs as a result of medical illness, even without previously recognized diabetes - especially among critically ill patients with cardiovascular disease (CVD) ${ }^{2,3}$ For example, the Euro Heart Survey found that $36 \%$ of patients without a history of diabetes who presented with acute manifestations of coronary artery disease had impaired glucose tolerance; another $22 \%$ had newly diagnosed diabetes. ${ }^{3}$ Likewise, in a prospective analysis of patients presenting with acute myocardial infarction (MI) and no history of diabetes, 35\% had impaired glucose tolerance and $31 \%$ had unrecognized diabetes. ${ }^{2}$

Even normoglycemic patients or those with well-controlled diabetes before illness onset may develop hyperglycemia in response to acute metabolic stress, suggesting an irregularity in homeostatic regulation mechanisms that worsens with severity of illness. ${ }^{4}$ In a prospective cohort study of 100 patients admitted to a medical intensive care unit (ICU), including 51 patients with normal glucose levels at baseline, nearly all experienced some degree of hyperglycemia. ${ }^{4}$ The substantial influence of even small increases in glucose levels was evident in that patients with glucose levels in the higher ranges of normoglycemia before admission had more frequent and more severe hyperglycemia in the ICU than did those with glucose levels within the lower range of normoglycemia (Figure 1). ${ }^{4}$ 


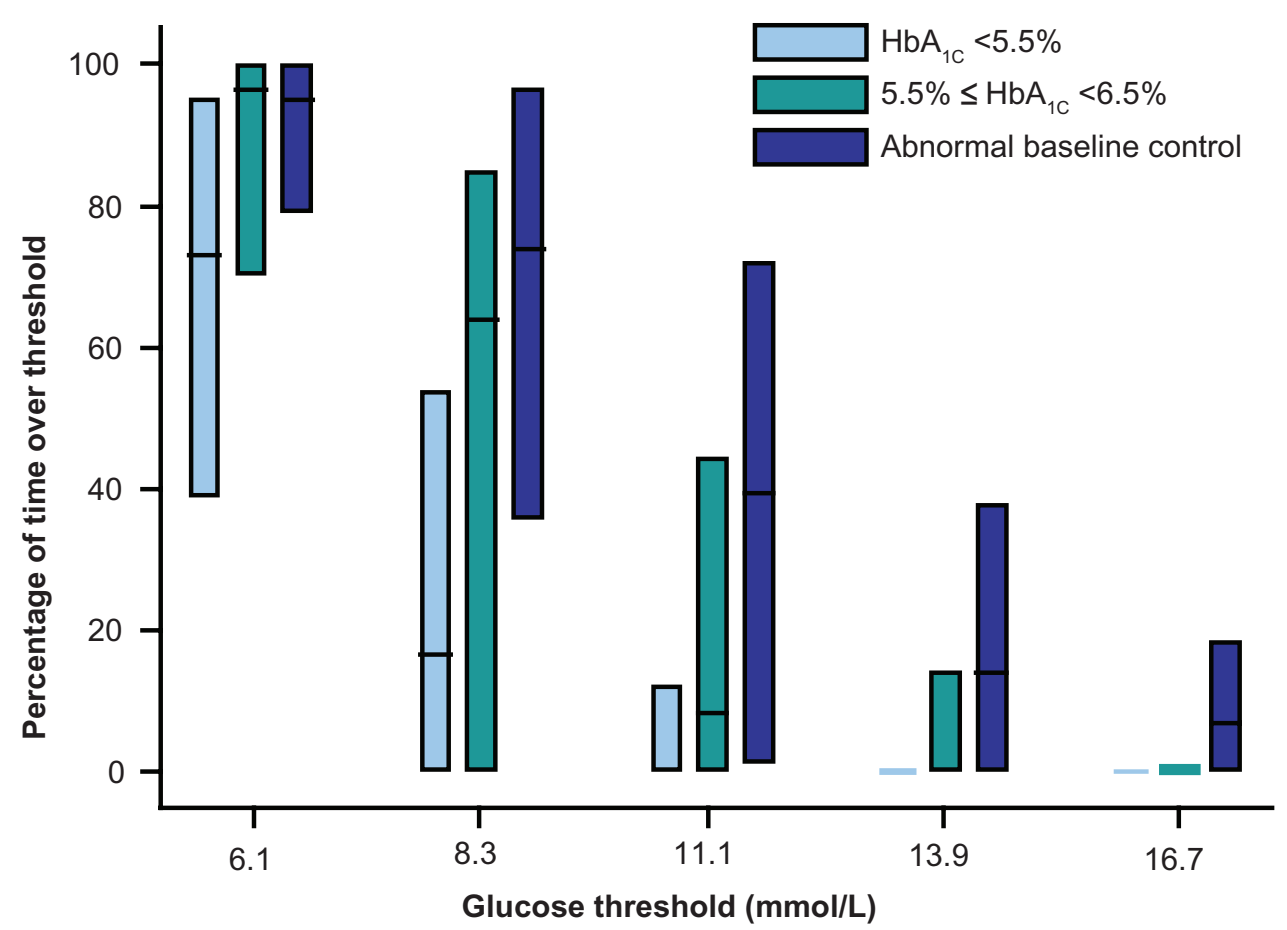

Figure I Percentage of time (median and quartile bounds) over glucose thresholds varied in patients admitted to the medical intensive care unit according to low-normal $\left(\mathrm{HbA}_{\mathrm{IC}}<5.5 \%\right)$, high-normal $\left(5.5 \% \leq \mathrm{HbA}_{\mathrm{IC}}<6.5 \%\right)$, and abnormal baseline glucose levels. Glucose threshold values can be converted to conventional units (mg/dL) by multiplying by the conversion factor 0.0555 .

Copyright @ 2004. Adapted with permission from AM College of Chest Medicine. Cely CM, Arora P, Quartin AA, Kett DH, Schein RM. Relationship of baseline glucose homeostasis to hyperglycemia during medical critical illness. Chest. 2004;126(3):879-887. ${ }^{4}$

Abbreviation: $\mathbf{H b A}_{1 \mathrm{c}}$, glycated hemoglobin.

It is now recognized that uncontrolled hyperglycemia has a negative effect on clinical outcomes in hospitalized patients. Many studies over the past 2 decades have demonstrated that short- and long-term mortality rates following acute MI are significantly higher when hyperglycemia is present, with or without established diabetes. ${ }^{5-11}$ This suggests that hyperglycemia, rather than diabetes status, influences morbidity and mortality risk. In fact, a study by Umpierrez and colleagues observed that hospitalized patients (admitted to general wards) with newly discovered hyperglycemia had significantly higher in-hospital mortality than those with normoglycemia or previously diagnosed diabetes (16\% versus $1.7 \%$ and $3 \%$, respectively, $P<0.01$ ). Newly recognized hyperglycemia was also associated with worse functional outcomes. ${ }^{12}$ Patients exhibiting stress hyperglycemia upon admission with acute MI have been shown to have a heightened risk of congestive heart failure (CHF) or cardiogenic shock compared with patients without hyperglycemia. ${ }^{11}$ This association between stress hyperglycemia and risk of CHF or shock has been observed in patients without diabetes and not present in patients with diabetes. ${ }^{11}$ In a retrospective study of 197 patients with acute MI without diabetes, admission plasma glucose level was an independent predictor of hospitalization for heart failure $(P=0.0034) .{ }^{9}$ In addition, a recent study showed that insulin resistance is an independent predictor of left ventricular diastolic disorder (LVDD) prevalence and severity in patients without diabetes. Insulin resistance was associated with: metabolic syndrome, LVDD, and obesity. The authors indicated that in patients with insulin resistance, the risk for LVDD is already elevated, even before the development of diabetes, therefore, these patients may be a target group for heart failure prevention. ${ }^{13}$

Several landmark studies have demonstrated that aggressive treatment of hyperglycemia with insulin therapy can reduce morbidity and mortality in critically ill patients, ${ }^{14,15}$ patients undergoing coronary artery bypass graft (CABG),${ }^{10}$ and post-MI patients with diabetes. ${ }^{16}$ These data have increased emphasis on managing hyperglycemia in hospitalized patients - especially the critically ill and those with CVD - and have led the American Diabetes Association (ADA) to update its guidelines for managing in-hospital hyperglycemia. The ADA 2010 Standards of Medical Care in Diabetes now recommend that insulin therapy be initiated for persistent hyperglycemia starting at $\leq 10.0 \mathrm{mmol} / \mathrm{L}$ $(\leq 180 \mathrm{mg} / \mathrm{dL}) .{ }^{17}$ Blood glucose levels should be maintained at 7.8 to $10.0 \mathrm{mmol} / \mathrm{L}$ (140 to $180 \mathrm{mg} / \mathrm{dL}$ ) for most critically 
ill patients and are most effectively achieved via intravenous insulin protocols. ${ }^{17}$ The 2009 American Association of Clinical Endocrinologists/ADA Consensus Statement on Inpatient Glycemic Control recommends a starting threshold no higher than $10.0 \mathrm{mmol} / \mathrm{L}(180 \mathrm{mg} / \mathrm{dL})$. Once IV insulin therapy has begun, blood glucose should be maintained between 7.8 and $10.0 \mathrm{mmol} / \mathrm{L}$ (140 and $180 \mathrm{mg} / \mathrm{dL}$ ), with targets $<6.1 \mathrm{mmol} / \mathrm{L}(<110 \mathrm{mg} / \mathrm{dL})$ not recommended. ${ }^{18}$

It should be noted that insulin therapy is not without potential harm. One meta-analysis found that tight glucose control in critically ill patients resulted in an increased risk of hypoglycemia. ${ }^{19}$ A small $(\mathrm{N}=13)$ study of healthy males designed to determine the body's response to the stress of hypoglycemia found an increase in proinflammatory cytokines, markers for lipid peroxidation, reactive oxygen species, and leukocytosis. Further examination is necessary to determine whether this is an adaptive response to the body's efforts to maintain glucose homeostasis under such stress. ${ }^{20}$

This paper reviews the underlying mechanisms believed to be responsible for the association between hyperglycemia and poor outcomes in critically ill patients and patients with cardiovascular events, as well as the biologic rationale for the benefits of insulin therapy in these patients.

\section{Hyperglycemia, inflammation, and atherogenesis}

Many data from in vitro and epidemiologic studies have suggested that insulin is potentially atherogenic. ${ }^{21-23}$ This arose from the finding that most patients with diabetes and at risk for vascular complications exhibit hyperinsulinemia due to compensation for insulin resistance, which is associated with atherogenic risk (eg, dyslipidemia, hypertension, procoagulant state). The notion that insulin itself is cardiotoxic or vasculotoxic, however, is inconsistent with more recent clinical outcomes, especially those observed in long-term follow-up of studies such as the United Kingdom Prospective Diabetes Study (UKPDS). ${ }^{24}$ Researchers now believe that hyperglycemia rather than the hyperinsulinemia of diabetes actually induces inflammatory changes and oxidative stress, which harm cardiovascular and endothelial function. ${ }^{25-29}$ Shown in Table 1 are the deleterious effects of hyperglycemia on endothelial and vascular function in patients with type 1 and type 2 diabetes with associated hyperlipidemia and insulin resistance. ${ }^{30}$

Insulin resistance, one of the 2 major contributors to type 2 diabetes, appears to play an important role in chronic cardiovascular risk. Its exact influence in atherogenesis is poorly understood, but several relationships appear to be
Table I Deleterious effects of hyperglycemia on endothelial and vascular function (as seen in patients with type 2 diabetes in association with dyslipidemia and insulin resistance $)^{61}$

\begin{tabular}{ll}
\hline AGEs activation & $\uparrow$ Vascular permeability \\
& $\uparrow$ Inflammatory cytokines \\
& $\uparrow$ Tissue factor \\
& $\uparrow$ Thrombomodulin \\
& $\uparrow$ Vasoconstriction \\
& $\uparrow$ Platelet adhesion \\
& $\uparrow$ Leukocyte adhesion \\
& $\uparrow$ Vascular smooth muscle cell growth \\
& $\uparrow$ Endothelin-I \\
$\uparrow$ PKC activation & $\uparrow$ Renin-angiotensin system \\
& $\uparrow$ Vascular permeability \\
$\uparrow$ Platelet and coagulation system & $\uparrow$ IIB/Illa receptors \\
& $\uparrow$ Clotting factors \\
activation & $\uparrow$ PAI-I \\
& $\downarrow$ Antithrombin III \\
$\downarrow$ PPAR activation & $\uparrow$ NFKB \\
& $\uparrow$ ROS \\
& $\uparrow$ Inflammatory cytokines
\end{tabular}

Abbreviations: AGEs, advanced glycation end products; PKC, protein kinase C; PPAR, peroxisome proliferator-activated receptor; IIB/IIla, glycoproteins IIB/IIla; PAI-I, plasminogen activator inhibitor-I; NFאB, nuclear factor $\kappa B$; ROS, reactive oxygen species.

involved. Insulin resistance, inflammation, and atherogenesis are linked by a common series of metabolic defects, including dyslipidemia and hypercoagulability. ${ }^{31}$ With insulin resistance, especially in patients with 4 or 5 aspects of the metabolic syndrome, deregulation of proinflammatory and anti-inflammatory cytokine production (eg, increased levels and activity of interleukin- 6 and tumor necrosis factor- $\alpha$ ) contributes to oxidative stress. The resultant generation of reactive oxygen species, combined with hypercholesterolemia and insulin resistance, apparently contributes to endothelial dysfunction.

Mechanisms involved in endothelial dysfunction in patients with diabetes, its impact on vascular complications, and potential targets of therapeutic intervention have been reviewed elsewhere. ${ }^{28,29}$ Relatively acute endothelial dysfunction and longer-term endothelial damage result from oxidative stress. Insulin therapy may reverse short-term endothelial dysfunction. ${ }^{32}$ Figure 2 shows a schematic of how insulin infusion therapy to treat hyperglycemia during critical illness may protect the endothelium by downregulation of inducible nitric oxide synthase. ${ }^{32}$ Subanalysis of a large, randomized controlled study of intensive insulin therapy in critically ill patients demonstrated how intensive insulin therapy suppressed inducible nitric oxide synthase gene expression in postmortem liver and skeletal muscle (via reduced nuclear factor $\kappa \mathrm{B}$ $[\mathrm{NF}-\kappa \mathrm{B}]$ activation), and reduced circulating nitric oxide levels in survivors and nonsurvivors. Biochemical changes reflected 


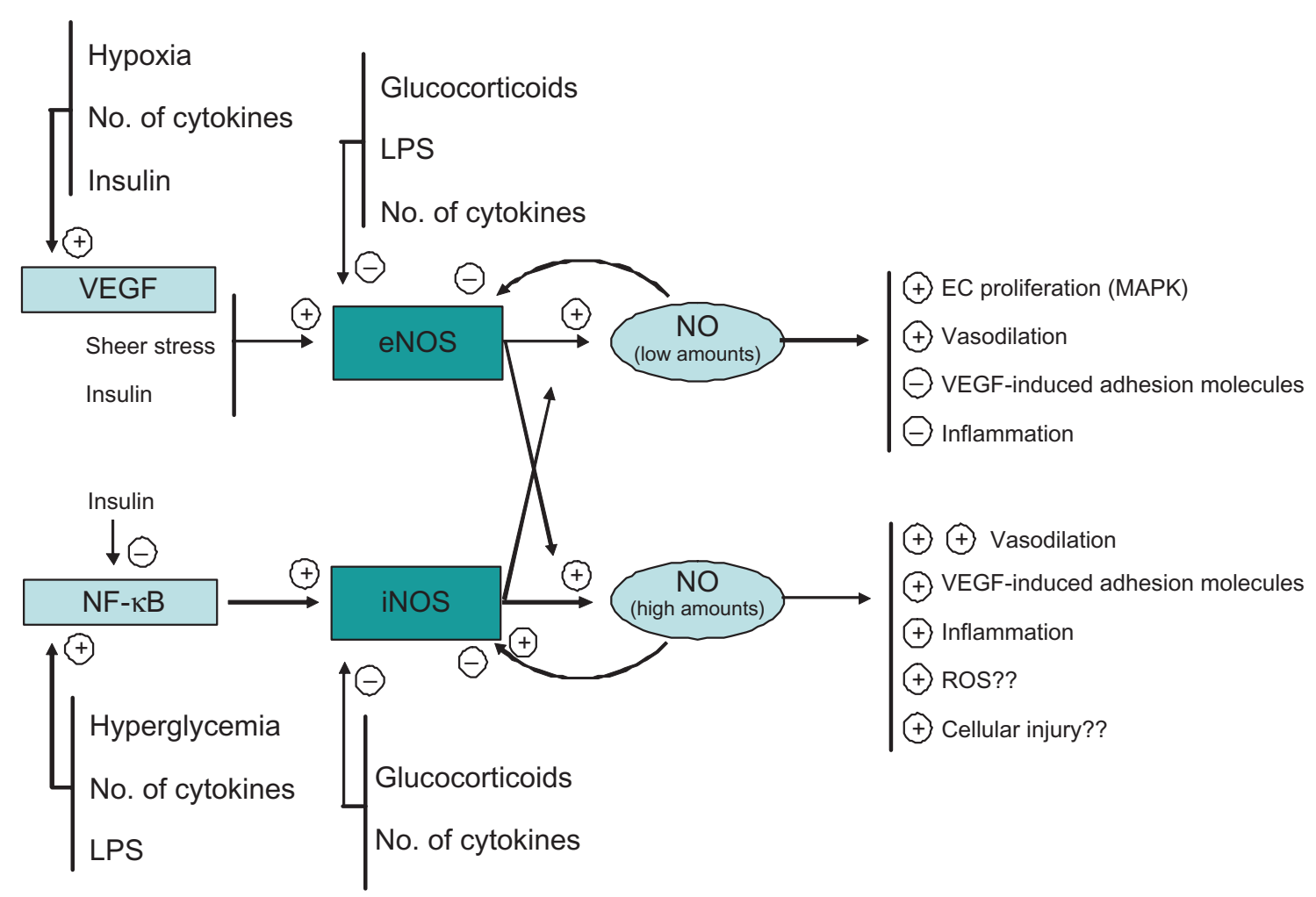

Figure 2 Model for effects of intensive insulin therapy on endothelial function in critically ill patients. Low concentrations of nitric oxide (NO), normally generated by endothelial nitric oxide synthase (eNOS), are likely to be beneficial for the endothelium and organ function. However, high concentrations of NO produced by upregulation of inducible nitric oxide synthase (iNOS) may contribute to excessive vasodilation, endothelium dysfunction, and tissue injury. Prevention of hyperglycemia during critical illness via insulin infusion may protect the endothelium by modifying eNOS and/or iNOS expression and activity.

Copyright @ 2005. Reprinted with permission from American Society for Chemical Investigation. Langouche L, Vanhorebeek I, Vlasselaers D, et al. Intensive insulin therapy protects the endothelium of critically ill patients. J Clin Invest. 2005; I I (8):2277-2286. ${ }^{32}$

Abbreviations: EC, endothelial cell; LPS, lipopolysaccharide; MAPK, mitogen-activated protein kinase; NFkB, nuclear factor $\kappa B$; ROS, reactive oxygen species; VEGF, vascular endothelial growth factor.

reduced endothelial activation, which contributes to the risk of organ failure and death in critically ill patients. The endothelial effects in this subanalysis explained a statistically significant portion of improved patient outcomes clinically associated with intensive insulin therapy. ${ }^{32,33}$

Using a model of critical illness, Ellger et al suggested that glycemic control helps maintain proper endothelial vasodilatory function indirectly through the actions of arginine and asymmetrical-dimethylarginine. ${ }^{34}$ Asymmetrical-dimethylarginine primarily cleared by dimethylarginine-dimethylaminohydrolase is an endogenous inhibitor of nitric oxide synthetase that increases during critical illness and predicts mortality and morbidity. Although insulin does not directly affect dimethy larginine-dimethylaminohydrolase, glucose control restores its activity, whereas uncontrolled hyperglycemia reduces it. Additionally, inhibition by insulin of plasminogen activator protein-1, an inhibitor of fibrinolysis, may help dissolve clots that form in acute MI. ${ }^{35}$

Longer-term biochemical or structural endothelial damage (see revised classic model of atherosclerosis in $\operatorname{Ross}^{36}$ ) can initiate a cascade of atherogenic activity in the vascular wall, including entrapment of atherogenic molecules, triggering of immunologic activity, promotion of adhesion molecules, and development of lipid-laden foam cells that form the basis for plaque production. ${ }^{31}$ Thus insulin resistance initiated by poor control of glycemic levels, rather than by insulin itself, may stimulate atherosclerosis. In the UKPDS intensive-treatment arm neither insulin nor insulin secretagogues were associated with increased vascular events, MI, or death. ${ }^{37}$ Interestingly, the long-term outcome of the UKPDS intensive glucose policy for sulfonylureas and insulin has recently been reported to show improvement in all-cause mortality, diabetes-related death, and significant reduction in MI. The reduction occurred despite the intensive policy group having had similar glycemic control over the past 10 years; it may represent a "legacy effect" of earlier glycemic control. ${ }^{24,38}$

Clinical studies have shown that patients with chronically elevated insulin levels due to insulin therapy have reduced insulin resistance but no increased risk of atherosclerosis or CVD. In some cases, individuals benefit from 
insulin exposure, experiencing reduced oxidative stress and improved endothelial function (ie, anti-inflammatory benefit)..$^{37,39}$ de Jager and colleagues linked the development of type 2 diabetes to the combination of endothelial dysfunction and low-grade inflammation, reporting a $>40 \%$ increased risk of cardiovascular mortality with this combination. ${ }^{40}$

Furthermore, elevated glucose levels have been shown to promote the production of reactive oxygen species, significantly increasing its generation by both mononuclear and polymorphonuclear cells within 3 hours after glucose challenge. ${ }^{41,42}$ Oral glucose intake (glucose tolerance test) also significantly increased binding of the transcription factor NF- $\mathrm{KB}$ in mononuclear cell nuclear extracts, indicating that pro-oxidant and proinflammatory activity follows the intake of excessive macronutrients. ${ }^{42}$ In another study, oxidative stress, as estimated from urinary excretion of free 8-iso prostaglandin $\mathrm{F} 2 \alpha$, was higher in patients with hyperglycemia resultant from type 2 diabetes than in nondiabetic controls matched for age and sex. ${ }^{43}$ These pathophysiologic findings confirm a relationship between variations in glucose exposure, endothelial dysfunction, and atherogenesis independent of insulin levels. When 1548 patients admitted to a surgical ICU received insulin infusion or conventional therapy to achieve blood glucose levels of 4.4 to $5.6 \mathrm{mmol} / \mathrm{L}$ ( 80 to $100 \mathrm{mg} / \mathrm{dL}$ ), lowering blood glucose rather than insulin dose reduced mortality $(P<0.0001){ }^{44}$

The role of insulin infusion versus glucose-insulinpotassium (GIK) therapy to achieve glycemic control and improve outcomes in critically ill patients has been investigated and debated. ${ }^{27,45}$ In general, GIK infusions may induce hyperglycemia, offset insulin's beneficial effects, and fail to control glucose levels. Insulin infusions may lower the proinflammatory effects of glucose and induce the anti-inflammatory effects of insulin. ${ }^{27,45}$

Recent studies in patients with type 2 diabetes have examined the hypothesis that insulin infusions may affect toll-like receptors (TLRs), major determinants of inflammatory response to viral, fungal, and bacterial pathogens. ${ }^{27}$ Insulin infusions significantly suppressed messenger RNA levels by $>25 \%$ for several of these receptors, including TLR-1, $-2,-4,-7$, and -9 , within 2 hours ( $P<0.05$ for all). DNA binding of PU.1, a major transcription factor regulating many TLR genes, was also suppressed $(24 \% \pm 10 \%, P<0.05) .{ }^{46}$

\section{Role of insulin in cardiovascular disease}

Several investigators have studied the impact of insulin on markers of atherosclerosis, indicating a compelling benefit.
A number of studies have shown a significant reduction in C-reactive protein increase in patients with CVD who were treated with insulin, during ST-segment elevation MI $(P<0.05)$ and CABG surgery $(P<0.05) .{ }^{47,48}$ These results indicate that insulin is associated with a decrease in the systemic inflammatory response. In a recent study involving 88 patients with a first MI who were scheduled to undergo $C A B G$ surgery (50 hyperglycemic patients and 38 normoglycemic [control] patients), ${ }^{33}$ hyperglycemic patients were randomized to intensive glycemic control (IGC; $\mathrm{n}=25$; glucose 4.4 to $7.8 \mathrm{mmol} / \mathrm{L}$ [ 80 to $140 \mathrm{mg} / \mathrm{dL}$ ]) or conventional glycemic control (CGC; $\mathrm{n}=25$; glucose: 10.0 to $11.1 \mathrm{mmol} / \mathrm{L}$ [180 to $200 \mathrm{mg} / \mathrm{dL}$ ]) for 3 days before surgery. Results showed that, compared with IGC patients, CGC patients had significantly higher infarct segment length $(P<0.05)$, myocardial performance index $(P<0.02)$, and wall motion scores $(P<0.01)$ but lower ejection fraction $(P<0.05)$. In the immediate postinfarct period, IGC was associated with a significant reduction of inflammatory cytokines, NF- $\mathrm{KB}$ activation, oxidative stress, and apoptotic cell death compared with $\mathrm{CGC}^{33}$. It is likely that treatment of hyperglycemia with insulin acts to counteract inflammatory response and poorer outcomes in critically ill patients by a dual mechanism of a direct anti-inflammatory effect of insulin as well as lowering the proinflammatory effects of glucose. ${ }^{27}$

Patients with type 2 diabetes randomized to placebo metformin, placebo metformin and insulin glargine, metformin only, or metformin and insulin glargine achieved significant reductions in blood glucose and glycated hemoglobin $\left(\mathrm{HbA}_{1 \mathrm{C}}\right)$ levels and $\mathrm{C}$-reactive protein in all treatment groups. However, reductions in C-reactive protein were not significantly different among patients using insulin (change from baseline: $-11.8 \%$; $95 \%$ confidence interval [CI]: $-18.7 \%$ to $-4.4 \%)$ compared with no insulin $(-17.5 \%$; 95\% CI: $-23.9 \%$ to $-10.5 \%$ ) (for difference, $P=0.25$ ), or among patients using metformin $(-18.1 \%$; $95 \%$ CI: $-24.4 \%$ to $-11.1 \%)$ compared with placebo $(-11.2 \% ; 95 \%$ CI: $-18.1 \%$ to $-3.7 \%$ ) (for difference, $P=0.17$ ). The authors note this study was limited to outpatients with stable type 2 diabetes and results may not pertain to the potential anti-inflammatory effects of insulin in critically ill patients. ${ }^{49}$

Thus far, no clinical studies examining the effects of insulin detemir on cardiovascular variables including lipid parameters or changes in carotid intima-media thickness have been published. However, the Copenhagen Insulin and Metformin Therapy (CIMT) trial will measure the change in carotid intima-media thickness, and other cardiovascular variables, following 18 months of treatment with insulins 
detemir and aspart. ${ }^{50}$ Carotid intima-media thickness often serves as a proxy for progression of macrovascular disease. The technique involves imaging an arterial wall segment of the common carotid arteries. ${ }^{50}$ Vehkavaara and Yki-Jarvinen studied the vascular effects of insulin glargine added to metformin in 11 patients whose type 2 diabetes was poorly controlled by metformin monotherapy. ${ }^{51}$ The patients receiving glargine experienced improvement in both endothelialdependent and endothelial-independent vasodilation at 3.5 years compared with noninsulin-treated control patients with diabetes ( $P<0.02$ for both treatment comparisons).$^{51}$ In another study, insulin aspart improved endothelial function in patients with type 2 diabetes by preserving flow-mediated vasodilation after a standard test meal $(P<0.01) .{ }^{52}$ Lautamaki and coworkers studied the effects of insulin infusion on endothelial activity in 43 patients with type 2 diabetes and a history of angina. ${ }^{53}$ Using traditional and nuclear imaging techniques, they observed increased myocardial blood flow in both ischemic and nonischemic regions, which helps improve endothelial function and preserve cardiac health. ${ }^{53}$

Finally, the Epidemiology of Diabetes Interventions and Complications (EDIC) study, an observational follow-up of the Diabetes Control and Complications Trial (DCCT), evaluated how aggressive insulin therapy affects cardiovascular architecture in patients with insulin-treated type 1 diabetes. ${ }^{54}$ Patients randomly assigned to conventional diabetes therapy $\left(611 ; \mathrm{HbA}_{1 \mathrm{C}}\right.$ goal, <9.0\%) were compared with patients receiving aggressive treatment $\left(618 ; \mathrm{HbA}_{1 \mathrm{C}}\right.$ goal, $<7.2 \%)$. Aggressive insulin therapy significantly reduced the degree of progression of intima-media thickening in the carotid artery $(0.032$ versus $0.046 \mathrm{~mm} ; P=0.01)$ and in the combined common and internal carotid arteries $(-0.115$ versus $0.007 \mathrm{~mm} ; P=0.2)$ after 6 years, compared with conventional diabetes therapy. ${ }^{54}$ Although this change has not been linked directly to cardiovascular outcome rates, the findings suggest a potential CVD benefit.

The major cardiovascular event rate has also been shown to be reduced in long-term follow-up of the EDIC study. During a mean 17 years of follow-up in the DCCT, 46 CVD events occurred in 31 patients intensively treated with a mixed-intermediate or rapid-acting insulin, compared with 98 events in 52 patients who received conventional treatment. There was a $42 \%$ decrease in cardiovascular events and a $57 \%$ decrease in the risk of nonfatal MI, stroke, or death from CVD in the intensive treatment group. ${ }^{55}$ Significant reductions in total cholesterol, low-density lipoprotein (LDL) cholesterol, and triglyceride levels also have been observed in the intensive-treatment group ( $P \leq 0.01)$, as well as a reduction in the development of LDL cholesterol levels $>4.1 \mathrm{mmol} / \mathrm{L}^{56}$

Ongoing studies, such as the ORIGIN (Outcome Reduction With Initial Glargine Intervention) trial will determine if maintaining normoglycemia with insulin glargine can reduce the risk of cardiovascular morbidity and/or mortality among outpatients with impaired fasting glucose, impaired glucose tolerance, or early type 2 diabetes who are at high risk for vascular disease. ${ }^{57}$ The ACCORD (The Action to Control Cardiovascular Risk in Diabetes) ${ }^{58}$ and ADVANCE (Action in Diabetes and Vascular Disease: Preterax and Diamicron Modified Release Controlled Evaluation $)^{59}$ study groups have recently published data indicating that intensive glycemic control $\left(\mathrm{HbA}_{1 \mathrm{C}}<6.0 \%\right.$ or $\leq 6.5 \%$, respectively) in patients with type 2 diabetes (ACCORD; mean age, 62 years; duration of diabetes, 10 years; ADVANCE; mean age, 66 years; duration of diabetes, 8 years) at high cardiovascular risk failed to reduce major cardiovascular events, and that it was actually associated with higher mortality (the ACCORD study). The implications of these results are not yet clear. Although future studies are unlikely to show improvements in CVD outcomes when $\mathrm{HbA}_{1 \mathrm{C}}$ values are $\leq 6.5 \%$, current evidence justifies maintaining $\mathrm{HbA}_{1 \mathrm{C}}$ goals at $<7.0 \%$ to reduce microvascular and neurologic morbidity and suggests that doing so may reduce CVD complications in the long term. ${ }^{60}$ It is important to note, however, that these studies examined outpatients with type 2 diabetes, as opposed to critically ill patients with hyperglycemia (discussed in this review) treated with a variety of glucose-lowering drugs, and the studies were therefore not specifically testing the effects of insulin therapy. Only $40.5 \%$ of patients in the intensive control arm of the ADVANCE study were prescribed insulin. ${ }^{59}$ Furthermore, more time may be needed for glycemic control to realize the reduction of MI risk. The 10-year follow-up of the UKPDS reported patients with type 2 diabetes who control glucose by intensive therapy (sulfonylurea or insulin, or metformin in overweight patients) had significant risk reductions for $\mathrm{MI}$ $(15 \%, P=0.01)$ and death from any cause $(13 \%, P=0.007)$ in the sulfonylurea-insulin group when compared with patients receiving conventional therapy (dietary restrictions); the metformin group also had significant risk reductions for MI $(33 \%, P=0.005){ }^{24}$

\section{Summary}

Hyperglycemia substantially increases the risk of morbidity and mortality among critically ill patients with CVD. Contrary to previous theories, the negative effect of hyperglycemia related to stress or uncontrolled diabetes on long-term 
outcomes in this patient subpopulation appears to be linked to the proinflammatory, oxidant stress, endothelial dysfunction, and atherogenic effects of hyperglycemia rather than to any metabolic alteration associated with hyperinsulinemia. Recognition of this alternative pathophysiologic paradigm and improved outcomes in patients treated with insulin have led to widespread interest in maintaining adequate glucose control in critically ill patients, and intense investigation into the best means by which to achieve relative normoglycemia throughout periods of acute illness.

\section{Acknowledgment}

The contents of the paper and opinions expressed within are those of the author, and it was the decision of the author to submit the manuscript for publication. The author contributed to the writing of this manuscript, including critical review and editing of each draft, and approval of the submitted version.

\section{Disclosure}

Editorial support was provided by Peter Mathisen, PhD, of Embryon and was funded by sanofi-aventis, US.

\section{References}

1. Centers for Disease Control and Prevention. National diabetes fact sheet: United States, 2007: general information. 2007.

2. Norhammar A, Tenerz A, Nilsson G, et al. Glucose metabolism in patients with acute myocardial infarction and no previous diagnosis of diabetes mellitus: a prospective study. Lancet. 2002;359(9324):2140-2144.

3. Bartnik M, Ryden L, Ferrari R, et al. The prevalence of abnormal glucose regulation in patients with coronary artery disease across Europe. The Euro Heart Survey on diabetes and the heart. Eur Heart J. 2004;25(21):1880-1890.

4. Cely CM, Arora P, Quartin AA, Kett DH, Schein RM. Relationship of baseline glucose homeostasis to hyperglycemia during medical critical illness. Chest. 2004;126(3):879-887.

5. Malmberg K, Rydén L. Myocardial infarction in patients with diabetes mellitus. Eur Heart J. 1988;9(3):259-264.

6. Meier JJ, Deifuss S, Klamann A, Launhardt V, Schmiegel WH, Nauck MA. Plasma glucose at hospital admission and previous metabolic control determine myocardial infarct size and survival in patients with and without type 2 diabetes: the Langendreer Myocardial Infarction and Blood Glucose in Diabetic Patients Assessment (LAMBDA). Diabetes Care. 2005;28(10):2551-2553.

7. Mehta SR, Yusuf S, Diaz R, et al. Effect of glucose-insulin-potassium infusion on mortality in patients with acute ST-segment elevation myocardial infarction: the CREATE-ECLA randomized controlled trial. JAMA. 2005;293(4):437-446.

8. Bolk J, van der Ploeg TJ, Cornel JH, Arnold AER, Sepers J, Umans VAWM. Impaired glucose metabolism predicts mortality after a myocardial infarction. Int J Cardiol. 2001;79(2-3):207-214.

9. Norhammar AM, Ryden L, Malmberg K. Admission plasma glucose. Independent risk factor for long-term prognosis after myocardial infarction even in nondiabetic patients. Diabetes Care. 1999;22(11): 1827-1831.

10. Furnary AP, Gao G, Grunkemeier GL, et al. Continuous insulin infusion reduces mortality in patients with diabetes undergoing coronary artery bypass grafting. J Thorac Cardiovasc Surg. 2003;125(5):1007-1021.
11. Capes SE, Hunt D, Malmberg K, Gerstein HC. Stress hyperglycaemia and increased risk of death after myocardial infarction in patients with and without diabetes: a systematic overview. Lancet. 2000;355(9206): $773-778$.

12. Umpierrez GE, Isaacs SD, Bazargan N, You X, Thaler LM, Kitabchi AE. Hyperglycemia: an independent marker of in-hospital mortality in patients with undiagnosed diabetes. J Clin Endocrinol Metab. 2002; 87(3):978-982.

13. Dinh W, Lankisch M, Nickl W, et al. Insulin resistance and glycemic abnormalities are associated with deterioration of left ventricular diastolic function: a cross-sectional study. Cardiovasc Diabetol. 2010; 9:63.

14. Van den Berghe $G$, Wouters $P$, Weekers $F$, et al. Intensive insulin therapy in critically ill patients. N Engl J Med. 2001;345(19):1359-1367.

15. Van den Berghe G, Wilmer A, Hermans G, et al. Intensive insulin therapy in the medical ICU. N Engl J Med. 2006;354(5):449-461.

16. Malmberg K, Rydén L, Efendic S, et al. Randomized trial of insulinglucose infusion followed by subcutaneous insulin treatment in diabetic patients with acute myocardial infarction (DIGAMI study): effects on mortality at 1 year. J Am Coll Cardiol. 1995;26(1):57-65.

17. American Diabetes Association. Standards of Medical Care in Diabetes - 2010. Diabetes Care. 2010;33(Supp1 1):S11-S61.

18. Moghissi ES, Korytkowski MT, DiNardo M, et al. American Association of Clinical Endocrinologists and American Diabetes Association consensus statement on inpatient glycemic control. Endocr Pract. 2009; 15(4):353-369.

19. Wiener RS, Wiener DC, Larson RJ. Benefits and risks of tight glucose control in critically ill adults: a meta-analysis. JAMA. 2008;300(8): 933-944.

20. Razavi NL, Kitabchi AE, Stentz FB, et al. Proinflammatory cytokines in response to insulin-induced hypoglycemic stress in healthy subjects. Metabolism. 2009;58(4):443-448.

21. Despres J-P, Lamarche B, Mauriège P, et al. Hyperinsulinemia as an independent risk factor for ischemic heart disease. N Engl J Med. 1996; 334(15):952-957.

22. Low Wang CC, Gurevich I, Draznin B. Insulin affects vascular smooth muscle cell phenotype and migration via distinct signaling pathways. Diabetes. 2003;52(10):2562-2569.

23. Montagnani M, Golovchenko I, Kim I, et al. Inhibition of phosphatidylinositol 3-kinase enhances mitogenic actions of insulin in endothelial cells. J Biol Chem. 2002;277(3):1794-1799.

24. Holman RR, Paul SK, Bethel MA, Matthews DR, Neil HA. 10-year follow-up of intensive glucose control in type 2 diabetes. NEngl J Med. 2008;359(15):1577-1589.

25. Van den Berghe G. How does blood glucose control with insulin save lives in intensive care? J Clin Invest. 2004;114(9):1187-1195.

26. Furnary AP, Wu Y, Bookin SO. Effect of hyperglycemia and continuous intravenous insulin infusions on outcomes of cardiac surgical procedures: the Portland Diabetic Project. Endocr Pract. 2004;10(Suppl 2): 21-33.

27. Dandona P, Chaudhuri A, Ghanim H, Mohanty P. Insulin as an antiinflammatory and antiatherogenic modulator. J Am Coll Cardiol. 2009; 53(Suppl 5):S14-S20.

28. Nacci C, Tarquinio M, Montagnani M. Molecular and clinical aspects of endothelial dysfunction in diabetes. Intern Emerg Med. 2009;4(2): 107-116.

29. Potenza MA, Gagliardi S, Nacci C, Carratu' MR, Montagnani M. Endothelial dysfunction in diabetes: from mechanisms to therapeutic targets. Curr Med Chem. 2009;16(1):94-112.

30. Thomas JE, Foody JM. The pathophysiology of cardiovascular disease in diabetes mellitus and the future of therapy. J Cardiometab Syndr. 2007;2(2):108-113.

31. Nigro J, Osman N, Dart AM, Little PJ. Insulin resistance and atherosclerosis. Endocr Rev. 2006;27:242-259.

32. Langouche L, Vanhorebeek I, Vlasselaers D, et al. Intensive insulin therapy protects the endothelium of critically ill patients. J Clin Invest. 2005;115(8):2277-2286. 
33. Marfella R, di FC, Portoghese M, et al. Tight glycemic control reduces heart inflammation and remodeling during acute myocardial infarction in hyperglycemic patients. J Am Coll Cardiol. 2009;53(16): 1425-1436.

34. Ellger B, Richir MC, Van Leeuwen PA, et al. Glycemic control modulates arginine and asymmetrical-dimethylarginine levels during critical illness by preserving dimethylarginine-dimethylaminohydrolase activity. Endocrinology. 2008;149(6):3148-3157.

35. Liu C, Yao J, Mercola D, Adamson E. The transcription factor EGR-1 directly transactivates the fibronectin gene and enhances attachment of human glioblastoma cell line U251. J Biol Chem. 2000; 275(27):20315-20323.

36. Ross R. The pathogenesis of atherosclerosis: a perspective for the 1990s. Nature. 1993;362(6423):801-809.

37. UK Prospective Diabetes Study Group. Intensive blood-glucose control with sulphonylureas or insulin compared with conventional treatment and risk of complications in patients with type 2 diabetes (UKPDS 33). UK Prospective Diabetes Study (UKPDS) Group. Lancet. 1998; 352(9131):837-853.

38. Chalmers J, Cooper ME. UKPDS and the legacy effect. N Engl J Med. 2008;359(15):1618-1620.

39. Leiter LA, Fitchett D. Optimal care of cardiovascular disease and type 2 diabetes patients: Shared responsibilities between the cardiologist and diabetologist. Atheroscler Suppl. 2006;7(1):37-42.

40. de Jager J, Dekker JM, Kooy A, et al. Endothelial dysfunction and lowgrade inflammation explain much of the excess cardiovascular mortality in individuals with type 2 diabetes. The Hoorn Study. Arterioscler Thromb Vasc Biol. 2006;26(5):1086-1093.

41. Mohanty P, Hamouda W, Garg R, Aljada A, Ghanim H, Dandona P. Glucose challenge stimulates reactive oxygen species (ROS) generation by leucocytes. J Clin Endocrinol Metab. 2000;85(8):2970-2973.

42. Dhindsa S, Tripathy D, Mohanty P, et al. Differential effects of glucose and alcohol on reactive oxygen species generation and intranuclear nuclear factor-kappaB in mononuclear cells. Metabolism. 2004;53(3): 330-334.

43. Monnier L, Mas E, Ginet C, et al. Activation of oxidative stress by acute glucose fluctuations compared with sustained chronic hyperglycemia in patients with type 2 diabetes. JAMA. 2006;295(14):1681-1687.

44. Van den Berghe G, Wouters PJ, Bouillon R, et al. Outcome benefit of intensive insulin therapy in the critically ill: insulin dose versus glycemic control. Crit Care Med. 2003;31(2):359-366.

45. Ceriello A, Zarich SW, Testa R. Lowering glucose to prevent adverse cardiovascular outcomes in a critical care setting. J Am Coll Cardiol. 2009;53(Suppl 5):S9-S13.

46. Ghanim H, Mohanty P, Deopurkar R, et al. Acute modulation of tolllike receptors by insulin. Diabetes Care. 2008;31(9):1827-1831.
47. Chaudhuri A, Janicke D, Wilson MF, et al. Anti-inflammatory and profibrinolytic effect of insulin in acute ST-segment-elevation myocardial infarction. Circulation. 2004;109(7):849-854.

48. Visser L, Zuurbier CJ, Hoek FJ, et al. Glucose, insulin and potassium applied as perioperative hyperinsulinaemic normoglycaemic clamp: effects on inflammatory response during coronary artery surgery. $\mathrm{Br} J$ Anaesth. 2005;95(4):448-457.

49. Pradhan AD, Everett BM, Cook NR, Rifai N, Ridker PM. Effects of initiating insulin and metformin on glycemic control and inflammatory biomarkers among patients with type 2 diabetes: The LANCET Randomized Trial. JAMA. 2009;302(11):1186-1194.

50. Lundby CL, Almdal T, Boesgaard T, et al. Study rationale and design of the CIMT trial: the Copenhagen Insulin and Metformin Therapy trial. Diabetes Obes Metab. 2009;11(4):315-322.

51. Vehkavaara S, Yki-Jarvinen H. 3.5 years of insulin therapy with insulin glargine improves in vivo endothelial function in type 2 diabetes. Arterioscler Thromb Vasc Biol. 2004;24(2):325-330.

52. Ceriello A, Cavarape A, Martinelli L, et al. The post-prandial state in type 2 diabetes and endothelial dysfunction: effects of insulin aspart. Diabet Med. 2004;21(2):171-175.

53. Lautamaki R, Airaksinen KE, Seppanen M, et al. Insulin improves myocardial blood flow in patients with type 2 diabetes and coronary artery disease. Diabetes. 2006;55(2):511-516.

54. Nathan DM, Lachin J, Cleary P, et al. Intensive diabetes therapy and carotid intima-media thickness in type 1 diabetes mellitus. $N$ Engl $J$ Med. 2003;348(23):2294-2303.

55. Nathan DM, Cleary PA, Backlund JY, et al. Intensive diabetes treatment and cardiovascular disease in patients with type 1 diabetes. $N$ Engl J Med. 2005;353(25):2643-2653.

56. Effect of intensive diabetes management on macrovascular events and risk factors in the Diabetes Control and Complications Trial. Am J Cardiol. 1995;75(14):894-903.

57. sanofi-aventis. The ORIGIN Trial (Outcome Reduction With Initial Glargine Intervention). Clinical Trials NCT00069784; 2007.

58. The Action to Control Cardiovascular Risk in Diabetes Study Group. Effects of intensive glucose lowering in type 2 diabetes. N Engl J Med. 2008;358(24):2545-2559.

59. The ADVANCE Collaborative Group. Intensive blood glucose control and vascular outcomes in patients with type 2 diabetes. $N$ Engl J Med. 2008;358(24):2560-2572.

60. Nathan DM. The role of glycemia management in the prevention of cardiovascular disease - starting over? Ann Intern Med. 2009;151(12): 888-889.

61. Aspray TJ, Nesbit K, Cassidy TP, Farrow E, Hawthorne G. Diabetes in British nursing and residential homes: a pragmatic screening study. Diabetes Care. 2006;29(3):707-708.
Clinical Epidemiology

\section{Publish your work in this journal}

Clinical Epidemiology is an international, peer-reviewed, open access journal focusing on disease and drug epidemiology, identification of risk factors and screening procedures to develop optimal preventative initiatives and programs. Specific topics include: diagnosis, prognosis, treatment, screening, prevention, risk factor modification, systematic

\section{Dovepress}

reviews, risk \& safety of medical interventions, epidemiology \& biostatical methods, evaluation of guidelines, translational medicine, health policies \& economic evaluations. The manuscript management system is completely online and includes a very quick and fair peer-review system, which is all easy to use. 